\title{
Cognitive Analysis on Prospective Mathematics Teachers' Reasoning Using Area and Tree Diagrams
}

\author{
Belén Giacomone ${ }^{\mathrm{ab}}$, Pablo Beltrán-Pellicer ${ }^{\mathrm{c}}$, and Juan D. Godino ${ }^{\mathrm{a}}$ \\ Corresponding author: Belén Giacomone (belen.giacomone@ gmail.com) \\ a Department of Didactics of Mathematics, University of Granada, Granada, 18071, Spain \\ ${ }^{\mathrm{b}}$ University of San Marino, Dogana, 47891, San Marino \\ cArea of Didactics of Mathematics, University of Zaragoza, Aragón, 50009, Spain
}

Keywords: fraction concept, cognitive analysis, diagrammatic reasoning, mathematics teacher education

International Journal of Innovation in Science and Mathematics Education, 27(2), 18-32, 2019

\begin{abstract}
One of the challenges in mathematics education research is to provide a comprehensive description of mathematical activity carried out by university students. Taking this challenge as an objective, this paper analyses the answers of 30 prospective teachers of primary education to a typical mathematics problem on fractions using area and tree diagrams. Theoretical and methodological tools from the onto-semiotic approach to mathematical knowledge and instruction support the cognitive analysis; hence, the underlying complexity of applying the area diagram to express a multiplicative reasoning should be highlighted. However, the structure of the system of practices that have to be carried out to solve the problem in the tree diagram are better aligned with this kind of reasoning. Furthermore, the use of the natural language in order to communicate the answer has been observed as a necessary register. This result lead to a deeper comprehension of the role played by these two types of diagrams and of the mathematical objects that emerge from such representations. As a conclusion, the type of analysis presented here is revealed as a strategic tool for instructors of primary education students to emphasize the importance of meanings negotiation.
\end{abstract}

\section{Introduction}

Diagrams are considered essential by many researchers and teachers, as these are fundamental for mathematical reasoning (Kadunz, 2016; Novick, 2004; Pantziara, Gagatsis, \& Elia, 2009), and for communication and problem solving in science (Hill, Sharma, O'Byrne, \& Airey, 2014; Roberts, Sharma, Sefton, \& Khachan, 2008). The literature suggests that involving students in the construction, experimentation, and manipulation of diagrammatic representations (Giardino, 2013), as well as in the reflection on their own productions (Bakker \& Hoffmann, 2005), allows generating opportunities for learning and strengthening connections between the different meanings of the mathematical concept represented. Nevertheless, the analysis of mathematical tasks and the different ways of approaching them is necessary to understand the potential difficulties and learning obstacles. A key point when considering mathematics teaching and learning processes is that the mathematical object itself is something different from its possible representations, and the relation between them is complex (Duval, 2006; Godino, Cajaraville, Fernández, \& Gonzato, 2012).

Within the context of teacher education, using different kinds of diagrams to support different ways of reasoning is an opportunity to reflect on professional practice. In this sense, Giacomone and others (e.g. Burgos, Beltrán-Pellicer, Giacomone, \& Godino, 2018; 
Giacomone, 2017; Giacomone, Díaz-Levicoy, \& Godino, 2018; Giacomone \& Godino, 2016; Giacomone, Godino, Wilhelmi, \& Blanco, 2016; Giacomone, Godino, Wilhelmi, and Blanco, 2018; Godino, Giacomone, Wilhelmi, Blanco, \& Contreras, 2016) have reported several educational experiences, most with prospective teachers of secondary and primary education, in regard to design of tasks which involve different types of diagrams. Those experiences pay attention to the existing dialectic between physical representations and their corresponding mathematical ideal/abstract objects, the latter being abstract entities, which emerge from the former ones. Furthermore, these authors consider that identifying and differentiating the different kinds of the mathematical practices, objects and processes in problem-solving tasks, which involve the use of diagrammatic representations should be a professional competence, both for the teacher educator and the mathematics teacher.

Connecting these key ideas about the use of diagrams within teacher instruction contexts, the objective of this research is to utilize area and tress diagrams to study which mathematical objects are activated by future primary education teachers when solving a problem regarding fractions. It is worth clarifying that the research topic in this work refers to the study of the configurations, or networks, of knowledge, that are established between these diagrams and their relationship with the abstract objects intertwined in them. The selection of a problem involving fractions (fractional representation of rational numbers) is just a trigger to motivate this reflection, given that it coincides with the curricular objective of the participating future teachers.

\section{Representation of fractions as teaching strategies}

Fractions, and therefore rational numbers, have been a key research subject in mathematics education for the last 20 years. Several authors have identified different obstacles which arise in the teaching and learning of fractions (Escolano \& Gairín, 2005; Koopman, Thurlings, \& Brok, 2017; Llinares \& Sánchez, 1988), and have also suggested strategies to overcome most of those obstacles (Lee, Brown, \& Orrill, 2011; NCTM, 2014; Moss, 2005). Despite this effort, "teaching fractions continues to be a major challenge faced by elementary and middle-school teachers" (Cramer \& Wyberg, 2009, sec. 1).

One teaching strategy is based on the construction or use of diagrams, visualizations, and other types of manipulative materials, which can be useful to establish connections between the different meanings of the fraction concept, such as fraction as the part-whole, fraction as operated, etc. This strategy if even more effective, if combined with real-life problems (Naiser, Wright, \& Capraro, 2004; Rau, 2016). Cramer and Wyberg (2009) investigated the effectiveness of different specific and pictorial models on student understanding of the partwhole construct for fractions; results showed limitations and strengths of the models.

Lee et al. (2011) analysed primary mathematics teacher reasoning of diagrammatic representations of fractions and decimals, and describe different strategies based on the responses. Throughout this research, the primary school teachers who took part showed a lack of both conceptual comprehension and cognitive skills to interpret the range of diagrammatic representations, which were drawn to model (or support) operations with fractions. The participants were unable to flexibly and effectively apply different strategies across the problem types (operation and drawn representation). However, the literature in general does not show results in terms of detailed analysis of the mathematical activity involved in the use of each diagram or strategy employed. 
Cramer and Wyberg (2009) suggest the need to be careful, as teachers, when selecting a model to build the understanding of fraction addition and multiplication. In order to achieve this, the teacher should be competent at analysing the selected tasks and at understanding the mathematical practices carried out by their students.

It is clear that fraction interpretation and the knowledge built upon that interpretation by future teachers is complex, as are the strategies that are incorporated when using different kinds of diagrams in solving mathematical problems. Detailed analysis of the mathematical activity carried out by prospective teachers will provide insight into learning difficulties, useful both for the teacher as well as researchers in mathematics education, in improving instruction.

\section{Theoretical framework}

The problem addressed in this paper is the analysis of the various types of objects involved in mathematical practices carried out with the support of tree and area diagrams, and attempting to highlight the synergies among the different types of objects involved. To perform this analysis, it is useful to consider theoretical tools from the Onto-Semiotic Approach (OSA) to mathematical knowledge (Font, Godino, \& Gallardo, 2013; Godino, Batanero, \& Font, 2007; Pino-Fan, Assis, \& Castro, 2015), in particular the onto-semiotic configuration of practices, objects, and processes. This tool facilitates the description and detailed analysis of the mathematical practices required to solve a problem.

Two key notions in the OSA framework are mathematical practice and object. Godino and Batanero (1998) define mathematical practice as any action or manifestation (linguistic or otherwise) carried out by somebody to solve mathematical problems and to communicate the solution to other people, so as to validate and generalize that solution to other contexts and problems. This involves an anthropological conception of mathematics, that is to say, mathematics as a human activity.

In the philosophy of mathematics, the term mathematical object usually refers to abstract objects such as classes, propositions or relationships. However, in the OSA framework the word object is used in a wider sense to mean any entity which is involved in some way in mathematical practice or activity and which can be separated or individualized, for example, a concept, a property, a representation, a procedure, etc. This conception of mathematical object is a very broad (or weak), reason why Godino et al. (2007, p. 130) introduce a categorization of six types of primary mathematical objects, taking into accounts their different role in mathematical activity. These are:

Languages (terms, expressions, notations) in different registers (written, oral, gesture, etc.) and representations;

Situations-problems (extra-mathematics applications, exercises);

Concepts-definition (examples: straight-line, dot, number, function);

Propositions (statements about concepts that require a justification);

Procedures (algorithms, operations, calculation techniques);

Arguments (statements used to justify or explain the propositions and procedures, whether 
they are deductive or otherwise).

These objects can be considered from different viewpoints (Figure 1); in this research, the following distinctions are useful:

Ostensive objects (material, perceptible) and non-ostensive objects (abstract, ideal, immaterial);

Extensive objects (particular) and intensive objects (general);

Personal objects (concerning individual subjects) and institutional objects (shared in an institution or community of practice).

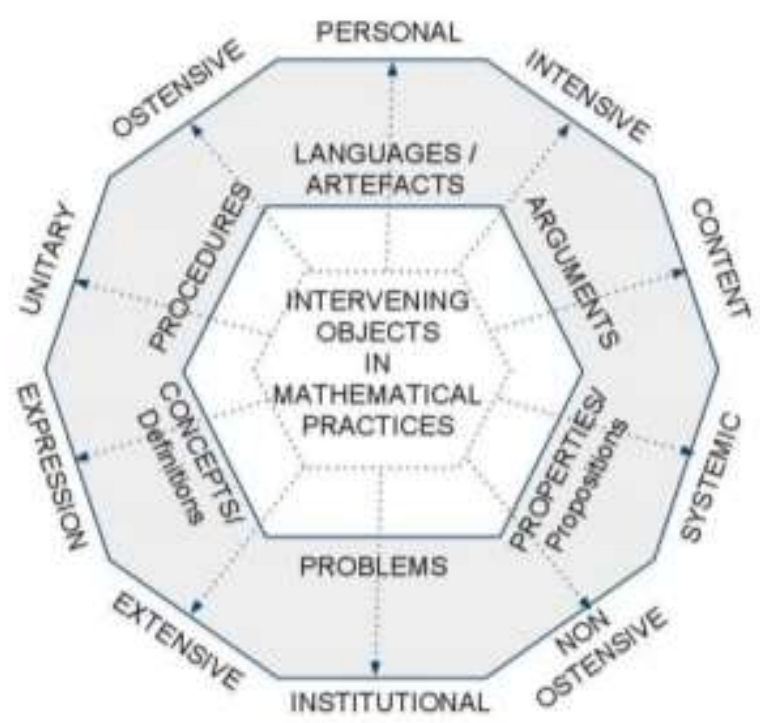

Figure 1: Onto-semiotic configuration (Font et al., 2013, p. 117)

When the objective is to analyse the expected, or expert mathematical practices involving the solution to a problem, such analysis will be epistemic, as the institutional point of view is considered (institutional meanings). However, when the objective is to analyse the answer given by a student, the emerging configurations will be cognitive (personal meanings), as is the case of this research work.

The different types of mathematical objects proposed by the OSA to analyse mathematical activity have been very helpful in analysing the mathematical practices involved in solving the problem on fractions and the intervening objects in these practices. This has made it possible to show the differences in students' cognitive performance when solving the problem by applying two different methods of resolution: area and tree diagram.

\section{Method}

This section begins describing the prospective teachers (university students) who served as case studies in the reported research. To follow, the methods, qualitative, exploratory, interpretative, and based on a teaching action, are described. The data collected allows analysis of the answers given by prospective teachers to gain a wider vision of the emerging mathematical knowledge. 


\section{Participants}

The research data analysed in this article comes from the assessment phase of a study process about the different diagrammatic representations when solving problems involving the use of fractions. The participants were 30 prospective teachers of primary education, who were firstyear students at a Spanish university.

\section{Procedure and data collection}

The objective of this research is to reveal how challenging the use of different representations for the same concept in mathematics education can be. As already mentioned and, according to some researchers, the arrangement of moments to explore different representations generates opportunities for the development of mathematical and didactic knowledge (Way, Bobis, \& Anderson, 2015). Considering the fact that our study took place in an academic term in which the participants were studying rational numbers, the implemented task to approach the research objective was specific to this topic.

The participants were asked to solve the following problem (Chart 1) by applying two distinct procedures: an area diagram and a tree diagram. This task has been utilised in pilot studies of future mathematics teachers and in-service teacher training (Giacomone, Godino et al., 2018).

Chart 1: The Martini Problem provided to the participants

A martini is a cocktail made with 5 parts of gin and 1 part of vermouth. Suppose that $2 / 5$ of the gin is alcohol and that $1 / 6$ of the vermouth is alcohol. What is the fraction of alcohol of a martini?

A) Solve the problem using an area diagram.

B) Solve the problem using a tree diagram.

The participants, when developing the different blocks of the syllabus, worked with visualizations and diagrammatic reasoning to address didactic situations, so we assert that the participants were familiar with solving problems using these two kinds of diagrams.

The following analysis attempts to inquire which concepts, propositions, languages, procedures and arguments emerge from the students' mathematical practices; this is the knowledge involved in network interpretation.

\section{Cognitive analysis}

Table 1 summarises the answers of the 30 prospective teachers participating in the study. The information provided in the table must be considered as a starting point to think why the tree diagram is more aligned with the arithmetic solution and why the participants are not comfortable when thinking in terms of area diagrams.

Table 1: Answers provided by the study participants to the Martini Problem

\begin{tabular}{lcccc}
\hline & \multicolumn{3}{c}{ Answers } & Total \\
\cline { 2 - 4 } Kind of diagram & Correct & Wrong & Unanswered & 30 \\
\hline Area diagram & 0 & 22 & 8 & 30 \\
\hline Tree diagram & 24 & 6 & 0 & \\
\hline
\end{tabular}


In order to answer these questions, some prototypic examples of strategies run by the students are depicted along the following subsections. For each one of them, an onto-semiotic analysis with the OSA theoretical tools is accomplished. Therefore, the knowledge put into play is easily identified, leading to a complete analysis of the exhibited mathematical activity.

\section{Regarding the use of area diagrams}

There is not a single participant in this study who solved the problem by supporting their reasoning by the construction and manipulation of an area diagram sequence that allows them to determine the fraction of alcohol in the martini. In other words, every area diagram was made after the participant had determined their answer. Although 13/36 is the correct answer, it was not clear how this result is obtained in each diagram.

The responses obtained with respect to the area diagram are classified into three types of cases, and the number of university students in each case is provided.

Case 1 ( 1 student): The student manages to somehow represent $13 / 36$ with an approximate diagrams sequence without specific written evidence of the use of arithmetical operations. However, the diagrams do not represent the combined fraction product and addition properly.

Case 2 (10 students): The students find a strategy to identify the alcohol content in the vermouth and in the gin in a single diagram. However, they do not manage to operate with the diagram in order to find a common measuring subunit, which allows them to identify the total alcohol fraction as the addition of vermouth and gin parts, turning to the arithmetic language to complete the answer to the problem.

Case 3 (11 students): The students draw incorrect or incomplete diagrams.

\section{Case 1}

A student proposes a four-diagram sequence (Figure 2), where each step denotes the part-whole partitioning scheme (Behr, Lesh, Post, \& Silver, 1983). In such a scheme, 'fractions' are considered as parts of a bigger whole. This participant uses natural language to denote the meaning of the drawings.

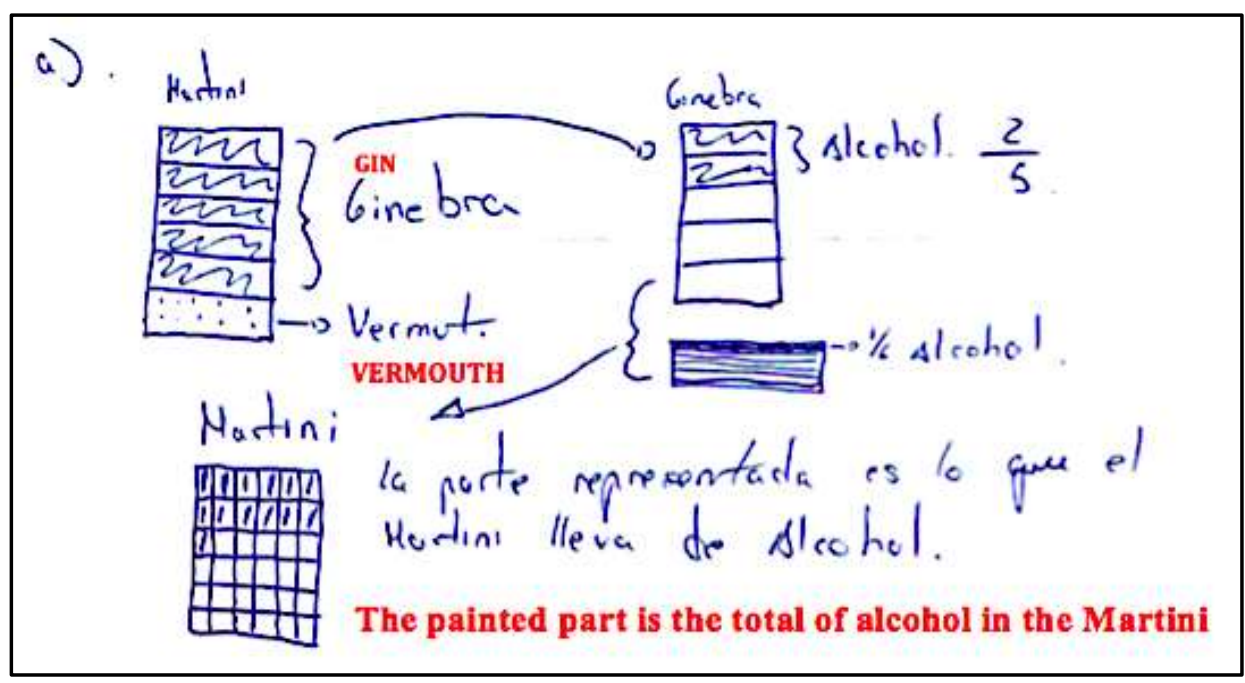

Figure 2: Answer based in area diagrams 
Ostensive and non-ostensive objects involved in Case 1:

Concept: fraction, as part of a whole;

Languages: in terms of Duval's theory (Duval, 2006) of semiotic representation registers, a conversion is applied, moving from the sequential register of natural language (task statement) to the graphic register (area diagram); specific treatments are carried out within this register in order to finally move onto the sequential register once again: "The painted part is the total of alcohol in the Martini". The use of arrows and curly brackets indicate the operations between diagrams;

Labels: they are necessary to understand the parts of the diagram;

Propositions: 4 propositions are proposed, being 3 partial solutions and the final diagrammatic solution;

Arguments: there are no arguments to justify the propositions raised. For the solution to be shared within a school institution, the written sequential register must accompany the graphic register;

Procedures: the first diagram represents the Martini as a whole, composed of 5 parts of gin and 1 of vermouth. Then, the student separates the gin from the vermouth, resulting in two new sub-diagrams, acting each one as a new whole and, thus, being partitioned in the same horizontal way as previously. In the last diagram of the sequence, the two subdiagrams of the second step are merged into the original whole, here partitioned into 36 parts. There is no cue along the sequence to justify this number of parts, neither drawn (the lines used to partition the whole are always horizontal in steps one and two) nor written. As Cramer and Wyberg (2009) point out in their results, strategies for this student were guided by his understanding of the common denominator algorithm for adding fractions.

The participant who solves the problem basing their reasoning on the use of area diagrams carries out processes of materialization of the concepts and operations with fractions implied in the statement and on the composition of the partial results that they obtain.

A more precise diagrammatic sequence would be required for the solution to be correct, as shown in Figure 3. 


\begin{tabular}{|c|c|c|c|c|c|}
\hline $\begin{array}{l}\text { Diagram } 1 . \\
\text { The unitary } \\
\text { quantity of } \\
\text { Martini }\end{array}$ & $\begin{array}{l}\text { Diagram } 2 . \\
\text { 5/6 Gin } \\
\text { 1/6 Vermouth }\end{array}$ & $\begin{array}{l}\text { Diagram } 3 . \\
2 / 5 \text { of } 5 / 6= \\
\text { Fraction of } \\
\text { alcohol in the } \\
\text { gin (green) }\end{array}$ & $\begin{array}{l}\text { Diagram } 4 . \\
1 / 6 \text { of } 1 / 6= \\
\text { Fraction of } \\
\text { alcohol in the } \\
\text { Vermouth } \\
\text { (orange) }\end{array}$ & $\begin{array}{l}\text { Diagram } 5 . \\
\text { The quantities } \\
\text { of alcohol in the } \\
\text { gin and in the } \\
\text { vermouth should } \\
\text { be expressed in } \\
\text { the same unit of } \\
\text { measurement. }\end{array}$ & $\begin{array}{l}\text { Diagram } 6 . \\
\text { The total } \\
\text { fraction of } \\
\text { alcohol in the } \\
\text { Martini is } 13 / 36\end{array}$ \\
\hline
\end{tabular}

\section{Figure 3: A complete sequence of diagrams required for a correct solution}

In Figure 3, the emerging fraction meaning is 'fraction as operator', as it is shown in Diagrams 3 and 4 (within Figure 3). The meaning of fraction as 'measure' can be observed in diagram 5, where it is clear that a measurement unit of size $1 / 36$ of the total mixture can be used in order to measure the alcohol fraction, a procedure which is finally and clearly depicted in the final diagram. After finding the right size of the measurement subunits by operating graphically with the diagrams, all that has to be done is to count how many measurement subunits (each one representing $13 / 36$ of the total) there are.

\section{Case 2}

Ten other university students utilise the concept of fraction as 'part of a whole which is partitioned in equal parts' and manage to represent the gin and vermouth parts. At the same time, they work on the concept of fraction as an 'operator', identifying with the corresponding reasoning the alcohol fraction which composes each one of the Martini ingredients (gin and vermouth alcohol fractions). However, in this case, the students do not manage to diagrammatically find a measurement subunit, which allows them to express the total alcohol fraction as the addition of the alcohol fraction of each ingredient, as they are operating with the part-whole model exclusively. As shown in Figures 4 and 5, for these participants, the meaning of 'fraction (and therefore, rational numbers) as measurement' is absent.

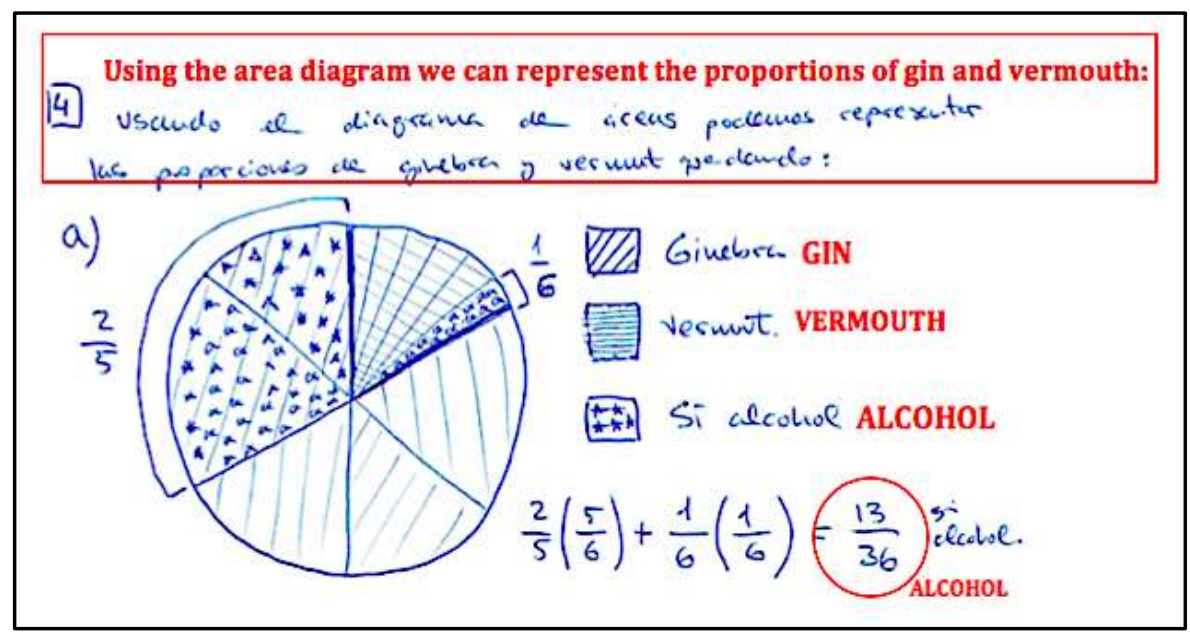

Figure 4: Example of a pie chart provided by a participant 


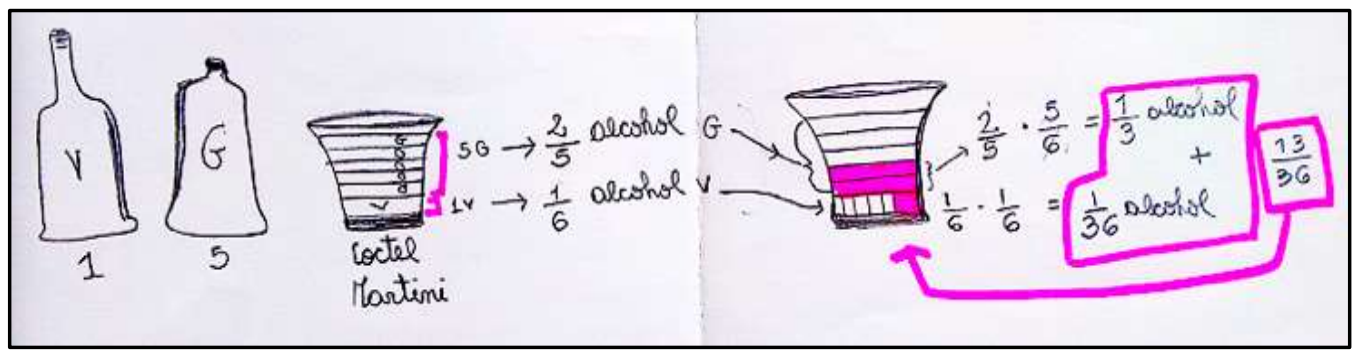

Figure 5: Example of a pictorial representation of a drinking glass to support reasoning, provided by a participant

Several authors have noticed difficulties implied by the use of some kinds of diagrams to represent operations with fractions. For instance, Moss (2005) suggested some limitations on the use of the circular model. She contended that the circle representation for the part-whole model for fraction supports additive thinking and not the needed multiplicative thinking required for understanding fractions. Hackenberg and Tillema (2009, p. 4) also influence the importance of a conceptual analysis in situations such as Figure 5. According to the authors, an immediate question the student faces could be: How do I take $2 / 5$ of $5 / 6$, and $1 / 6$ of $1 / 6$ ?

In this way, we consider that a clearer understanding of the efficiency of the models that are to be used in teaching is needed to represent fractions, and thus, the importance of documenting detailed analyses of the knowledge involved in such representations. Finally, these students are just using arithmetic calculations to find the solution, without connection to the diagrams; therefore it is impossible to answer the problem by means of the represented diagram.

\section{Case 3}

The 11 participants in this group represented, in an isolated rectangular area diagram, the fractions $5 / 6$ (gin part) and $1 / 6$ (vermouth part). At the same time they have operated with symbolic language to find the solution to the problem. On the other hand, 5 of these students have not reached the right answer, denoting difficulties to understand the problem, as shown in Figure 6.

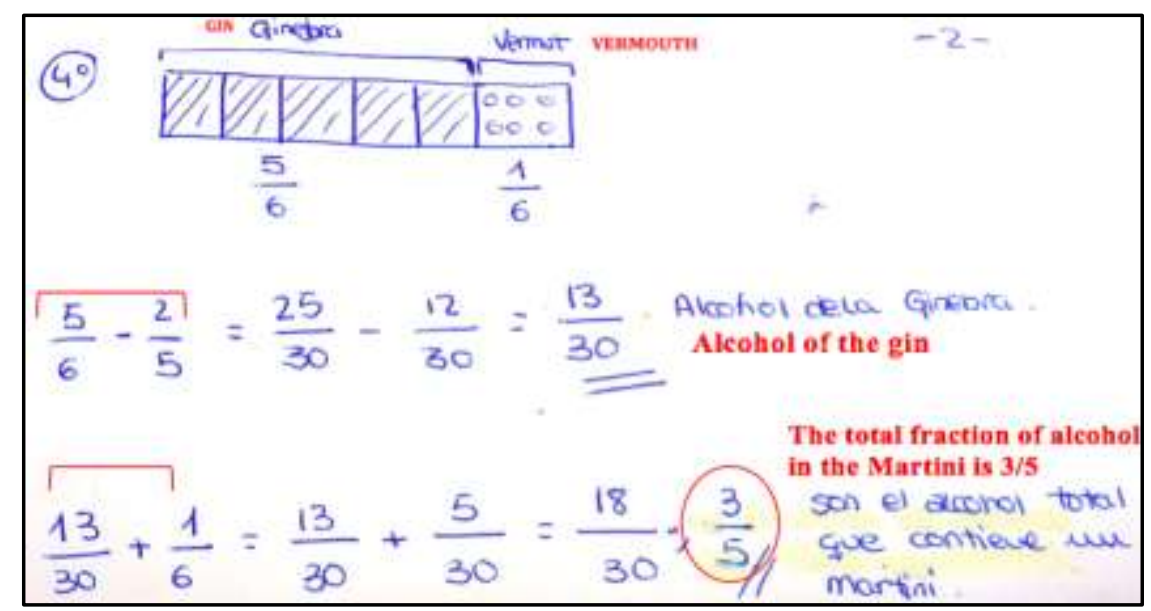

\section{Figure 6: Prototypical example of an incorrect solution}

In the particular case shown in Figure 6, firstly, the participant subtracts the gin fraction from the alcohol part of the gin, i.e., $(5 / 6-2 / 5)$. Then, the participant realizes that such an operation 
cannot be done to the vermouth, since it would lead to $1 / 6-1 / 6$, meaning that there is no alcohol in the vermouth. Finally, this participant decides to add up the partial results and thus utilizing incorrect reasoning.

\section{Regarding the use of tree diagrams}

The answers given by the participants show that they do not find too many difficulties in building a tree diagram to represent how the participants have solved the problem. Likewise, the conversion of the hierarchical structure of the diagram into arithmetic language is required to reach the right result, $13 / 36$, along with the use of natural language to support the actions carried out by the participant.

In this case, the solutions the participants' have produced can be classified into two distinct categories. To illustrate the classification, some examples of prototypical answers are included.

\section{Case 1 examples}

The 24 correct answers given by the participants are grouped in this Case 1, and the diagram shown in Figure 7 is provided as a prototypical example.

The cognitive analysis based on Figure 7 shows the importance the initial discursive practice of the student when trying to express the hierarchical structure of the problem, as well as to translation from natural to diagrammatic language. In Duval's terms, once the tree diagram is developed, the participant performs a conversion cognitive process to the arithmetic register. This process of transferring from one semiotic register to another semiotic register is not evident to the participant. The participant should carry out a splitting process of the system of elements that make up the diagram, distinguishing three hierarchical levels, and the units that make up the whole unit of each level, connectors, the fractions, and the operations with fractions that should be carried out. A splitting process of the partial calculation carried out at each branch of the tree should also be carried out in order to obtain the fraction of alcohol of the Martini and of the materialization of the calculation in the final arithmetic-diagrammatic expression $2 / 5(5 / 6)+1 / 6(1 / 6)=13 / 36$.

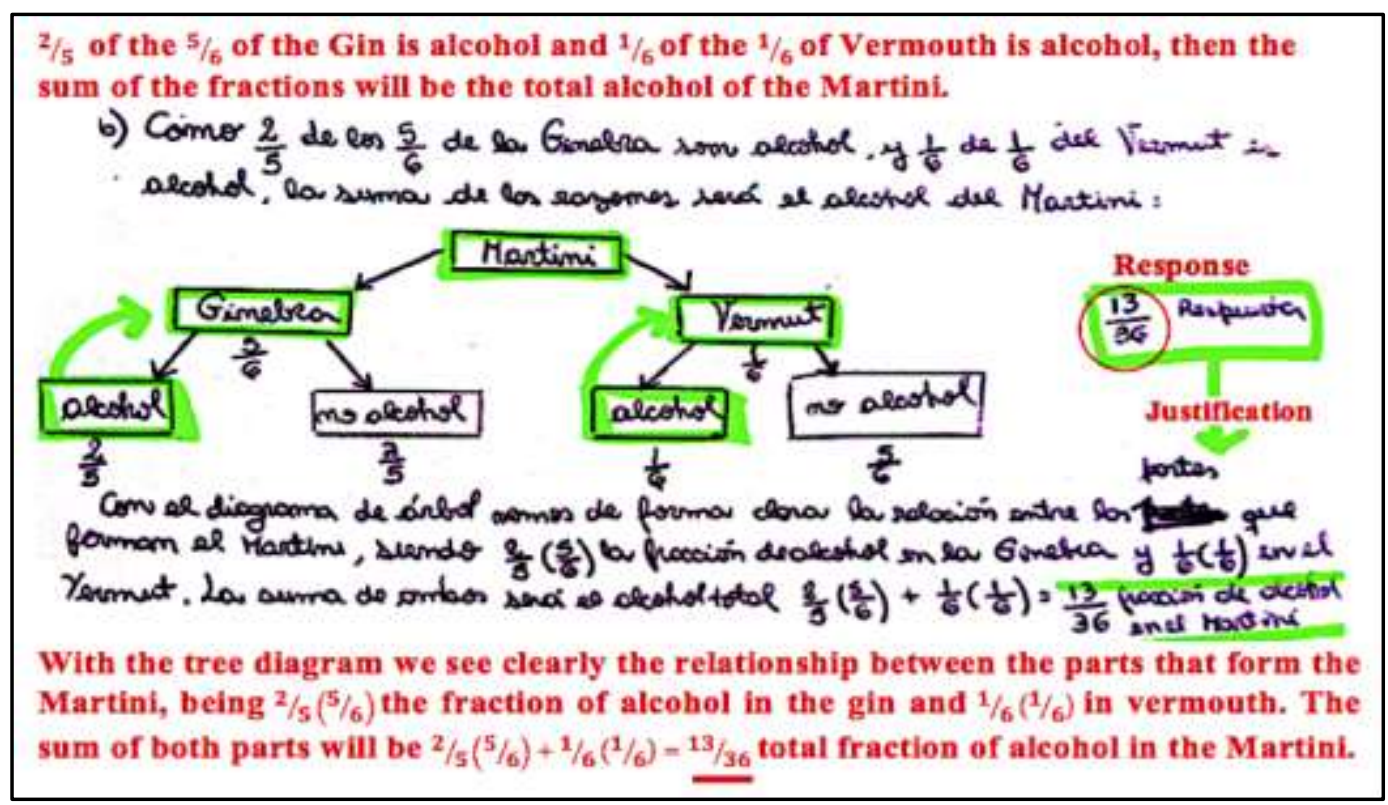

Figure 7: Prototypical example of a correct answer using tree diagram provided by a participant 
The represented diagram (Figure 7) can be analysed according to its three hierarchical levels, each of which represent a proposition made by the student who is solving the problem, the tree diagram being the final proposition justified by the written discursive practices.

The first level produces a division into two parts, gin and vermouth, indicating in each connector its corresponding fraction. The second level expresses the decomposition of the parts of gin and vermouth - which are now considered as unit quantities, in two new parts, alcohol and non-alcohol, indicating in each connector its corresponding fraction:

Concepts: levels of a diagram, connector, unit of quantity and fraction;

Representation agreement: the fractions over the connectors refer to the fractional relation between the quantities connected;

Procedures: splitting of a whole into equal parts.

In the third level, the amount of alcohol is represented. At this level it is very easy to solve the problem, since the parts are clearly identified in the diagram and highlight the sequential aspect of the resolution process:

Concepts: multiplication of fractions (fraction of a fraction); unit quantity; sum of fraction;

Procedures: multiplication of fractions; change of unit when changing from the first to the second level of the diagram (the volume of gin and vermouth are now considered new units which are divided); sum of fractions with different denominator;

Final proposition: the fraction of alcohol in the Martini is $13 / 36$;

Argument: supported by the use of arithmetic representation, tree diagram, and natural sequential language.

\section{Case 2 examples}

Among the 6 correct answers, some difficulties in expressing the second hierarchical level can be observed, as shown in a prototypical answer provided in Figure 8 . The participant does not manage to represent the second level of the diagram, which is required to deal with the composition of gin and vermouth parts. Instead, the participant steps away to represent the alcohol part within each ingredient. Therefore, they are not correctly considering the concept of fraction associated with the tree diagram.

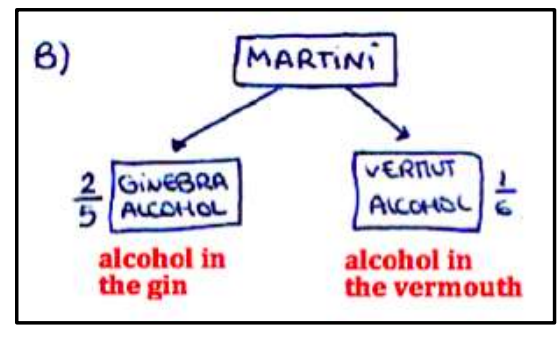
Figure 8: Prototypical example of an incorrect representation using tree diagram
provided by a participant 


\section{General discussion}

As a product of empirical results, Hoffman (2011, p. 196) noted that diagrammatic reasoning may provide some kind of cognitive support, but the nature of the reasoning process depends on the chosen representation system. In our case, it was clear that the participants were more efficient when solving the problem by means of a tree diagram. This may be because the tree diagram represents the structure of the operations involved in the process in a simplest way. Hence, the concept of fraction, which is activated, is fraction as the ratio between some numbers of parts of a whole that is equally-partitioned. The idea of 'fraction of fraction' can be easily identified when composing the two lower levels of the diagram (Figure 7), whereas the addition of the resulting fractions is reflected on the sideways disposition of the two branches (left and right).

On the other hand, the use of the area diagram activates another meaning of fraction, as 'operator over an area quantity'. This is a meaning that is more complicated in being represented diagrammatically and university students are usually not used to working this way. For this reason, the participants in this study failed to use the area diagram.

It was also observed that in all the diagrams represented, no participants focused their attention on the importance of the 'equal areas' that appear in the fractioning, i.e., 'to divide a whole into equal parts'. Although for Escolano and Gairín (2005) this fact is part of a didactic obstacle produced in school instruction by hiding the existence of a measurement process in the construction of the part-whole meaning (p. 3), in this work we do not consider it to be of relevance. Our analysis agrees with Sherry's position (Sherry, 2009) about the use of diagrams in mathematical practices; in this sense, more than building a specific diagram, the important point is the mathematical knowledge implied in this diagram, i.e., the non-ostensive objects involved in such representations, which are not visible anywhere.

With regards to the emphasis on symbolic language, it is clear that despite the broad agreement in the literature on the use of multiple representations to support learning, students rely on symbolic notation as a safe means of expressing the solution. When future teachers use other graphic representations, they do it only to illustrate solutions instead of adapting these representations to support the development of student understanding of rational numbers (Izsák, Orrill, Cohen, \& Brown, 2010). However, we consider that the use of diagrams or sequence of diagrams is not in itself explanatory of the resolution process. For example, in Figure 2 we find ourselves asking: what has the participant actually done? Why did the participant build a fourth diagram divided into 36 parts? Etc. It is necessary to ask the participants to incorporate discursive and operative practices to justify the given answer (Empson, 2003) and to make connections among representations (Moon, Brenner, Jacob, \& Okamoto, 2013). Thus, it is shown that visual-diagrammatic language must be accompanied by the contest of natural language to communicate the response, and that together with ostensive mathematical objects (visible and material objects) there is always a configuration of non-ostensible objects (abstract objects) that participate in the mathematical activity (Godino et al., 2012).

Finally, results have shown that the part-whole model of thought was dominant in the participants when solving the proposed task by drawing an area diagram, as expected, because it is the main paradigm in the teaching and learning of rational numbers. These results are to 
be expected, given that in Spain, as Escolano and Gairín (2005) pointed out, the part-whole relationship predominates in primary education. However, there were not any such diagrams supporting the reasoning of the mathematical actions carried out by the participants. Therefore, the role of the part-whole model as the main pillar over which the notion of rational number is built, should be, at the minimum, questioned.

\section{Final reflections: Implications for teacher education}

This work has addressed the cognitive analysis of the reasoning of a group of university students, as prospective mathematics teachers, when trying to solve a specific task which allows to connect different meanings of fractions, using two distinct types of diagrams (tree and area representations).

The a-priori analysis of the task showed the underlying complexity when applying the area diagram to express a multiplicative reasoning, and the participants' difficulties in this sense should be highlighted. On the other hand, the structure of the system of practices that must be carried out to solve the problem in the tree diagram is better aligned with this kind of reasoning, and therefore, the participants were more successful in solving the problem using this kind of diagram. Likewise, the results showed a strong tendency of the participants to use and trust in arithmetic-fractional operations (Izsák, 2008; Izsák et al., 2010; Way et al., 2015), both to justify building diagrams, and to express the solution. Despite these results, a limitation of this research was to omit the implementation of personalized interviews in order to obtain more information regarding the construction of the area diagrams, mainly in those cases where the answer is quite accurate, but the participant was indeed asked to justify adequately the solving process (Figure 2).

The use of the natural language to communicate the answer has been observed as a necessary register; the case of Figure 7 is an illustrative example, where the discursive practice associated with the graph is key to justifying the student's diagrammatic reasoning. The same should be noted for the area diagram.

Although it was not the main objective to focus on group interactions when sharing the individual answers during the experience, there was agreement with Way et al. (2015) on the fact that incorporation, construction, and exploration of representations of fractions were a central point for the growth of future teachers in the development of knowledge for teaching, becoming aware, also, that they needed to develop certain competencies in the use of diagrammatic representations ( $\mathrm{Rau}, 2016$ ).

On the other hand, as an implication for teaching education, from a teacher educator' point of view, the results presented here could be useful for thinking in terms of educational designs. This exploratory study provides a window onto the mathematical objects and processes involved in the use of different representations, and thus suggests the importance that mathematics educators have competence in the recognition of mathematical complexity when designing and implementing didactic tasks in general, and fractions in particular (Godino, Giacomone, Batanero, \& Font, 2017). This type of analysis is shown to be strategic for the educator as it allows reflections on possible learning difficulties (Cohen, 2004), both at the time for designing and selecting tasks and in the effective implementation in the classroom (Thompson \& Saldanha, 2003), and in effectively manage the dynamics of such affordances. 


\section{Acknowledgements}

Research carried out as part of the research project EDU2016-74848-P (FEDER, AEI), FQM-126 Group (Regional Government of Andalusia), and Project S36_17D-Research in Mathematics Education (Government of Aragon and European Social Fund).

\section{References}

Bakker, A., \& Hoffmann, M. H. G. (2005). Diagrammatic reasoning as the basis for developing concepts: a semiotic analysis of students' learning about statistical distribution. Educational Studies in Mathematics, 60(3), 333-358.

Behr, M. J., Lesh, R., Post, T. R., \& Silver, E. A. (1983). Rational number concepts. In R. Lesh \& M. Landau (Eds.), Acquisition of Mathematics Concepts and Processes (pp. 91-126). New York, NY: Academic Press.

Burgos, M., Beltrán-Pellicer, P., Giacomone, B., \& Godino, J. D. (2018). Prospective mathematics teachers' knowledge and competence analyzing proportionality tasks. Educação e Pesquisa, 44 (in press).

Cramer, K., \& Wyberg, T. (2009). Efficacy of different concrete models for teaching the part-whole construct for fractions. Mathematical thinking and learning, 11(4), 226-257.

Cohen, S. (2004). Teachers' professional development and the elementary mathematics classroom: Bringing understandings to light. Nueva Jersey: Routledge.

Duval, R. (2006). A cognitive analysis of problems of comprehension in a learning of mathematics. Educational Studies in Mathematics, 61(1-2), 103-131.

Empson, S. B. (2003). Low-performing students and teaching fractions for understanding: An interactional analysis. Journal for Research in Mathematics Education, 34(4), 305-343.

Escolano, R., \& Gairín, J. M. (2005). Modelos de medida para la enseñanza del número racional en Educación Primaria. Unión, 1, 17-35.

Font, V., Godino, J. D., \& Gallardo, J. (2013). The emergence of objects from mathematical practices. Educational Studies in Mathematics, 82(1), 97-124.

Giacomone, B. (2017). Onto-semiotic analysis of a mathematical modelling task. In Contreras et al. (Eds.), Proceedings of the $2^{\text {nd }}$ Virtual International Congress about Onto-Semiotic Approach (pp. 1-11). CIVEOS.

Giacomone, B., Díaz-Levicoy, D., \& Godino, J. D. (2018). Onto-semiotic tasks analysis involving statistical graphs in Primary Education. Revista digital Matemática, Educación e Internet, 18(1), 1-13.

Giacomone, B., \& Godino, J. D. (2016). Experiencia formativa para desarrollar una competencia didácticomatemática de futuros profesores [Formative experience to develop a didactic-mathematical competence of future teachers]. Proceedings of the XVI Congress of mathematics teaching and learning. Matemáticas, ni más ni menos (pp. 1-10). Jerez, Spain: CEAM.

Giacomone, B., Godino, J. D., Wilhelmi, M. R., \& Blanco, T. F. (2016). Recognition of practices, objects, and processes in solving mathematical tasks: a mathematics teacher's competence. In Berciano, A. et al. (Eds.), Investigación en Educación Matemática XX (pp. 269-277). Malaga, Spain: SEIEM.

Giacomone, B., Godino, J. D., Wilhelmi, M. R., \& Blanco, T. F. (2018). Developing the onto-semiotic analysis competence of prospective mathematics teachers. Revista Complutense de Educación, 29(4), 1-24.

Giardino, V. (2013). Towards a diagrammatic classification. The Knowledge Engineering Review, 28(3), $237-$ 248.

Godino, J. D., \& Batanero, C. (1998). Clarifying the meaning of mathematical objects as a priority area of research in Mathematics Education. In A. Sierpinska, \& J. Kilpatrick (Eds.), Mathematics education as a research domain: A search for identity (pp. 177-195). Dordrecht: Kluwer, A. P.

Godino, J. D., Batanero, C., \& Font, V. (2007). The onto-semiotic approach to research in mathematics education. ZDM, 39(1-2), 127-135.

Godino, J. D., Cajaraville, J. A., Fernández, T., \& Gonzato, M. (2012). Una aproximación ontosemiótica a la visualización en educación matemática. Enseñanza de las Ciencias, 30(2), 163-184.

Godino, J. D., Giacomone, B., Batanero, C., \& Font, V. (2017). Onto-Semiotic approach to mathematics teacher's knowledge and competences. Bolema, 31(57), 90-113.

Godino, J. D., Giacomone, B., Wilhelmi, M. R., Blanco, T. F., \& Contreras, A. (2016). Onto-semiotic analysis of visualization and diagrammatic reasoning tasks. In Proceeding of the 13th International Congress on Mathematical Educations. Hamburg, Germany: ICME. Retrieved from http://funes.uniandes.edu.co/8400/

Hackenberg, A. J., \& Tillema, E. S. (2009). Students' whole number multiplicative concepts: A critical constructive resource for fraction composition schemes. The Journal of Mathematical Behavior, 28(1), 1-18.

Hill, M., Sharma, M. D., O'Byrne, J., \& Airey, J. (2014). Developing and evaluating a survey for representational fluency in science. International Journal of Innovation in Science and Mathematics Education, 22(5), 22-42. 
Hoffmann, M. H. (2011). Cognitive conditions of diagrammatic reasoning. Semiotica, (186), 189-212.

Izsák, A. (2008). Mathematical knowledge for teaching fraction multiplication. Cognition and Instruction, 26(1), 95-143.

Izsák, A., Orrill, C. H., Cohen, A., \& Brown, R. E. (2010). Measuring middle grades teachers' understanding of rational numbers with the mixture Rasch model. Elementary School Journal, 110(3), 279-300.

Kadunz, G. (2016). Diagrams as means for learning. In A. Sáenz-Ludlow, \& G. Kadunz (Eds.), Semiotics as a tool for learning mathematics (pp. 111-126). SensePublishers.

Koopman, M., Thurlings, M., \& Brok, P. (2017). Factors influencing students' proficiency development in the fraction domain: the role of teacher cognitions and behavior. Research Papers in Education, 1-24.

Lee, S. J., Brown, R. E., \& Orrill, C. H. (2011). Mathematics teachers' reasoning about fractions and decimals using drawn representations. Mathematical Thinking and Learning, 13(3), 198-220.

Llinares, S., \& Sánchez, M. V. (1988). Fracciones: La relación parte-todo. Madrid: Síntesis.

Moon, K., Brenner, M. E., Jacob, B., \& Okamoto, Y. (2013). Prospective secondary mathematics teachers' understanding and cognitive difficulties in making connections among representations. Mathematical Thinking and Learning, 15(3), 201-227.

Moss, J. (2005). Pipes, tubes, and beakers: New approaches to teaching rational-number system. In Donovan, M., \& Bransford, J. D. (Eds.), How students learn: Mathematics in the classroom (pp. 309-350). Washington, D.C: The National Academies Press.

Naiser, E. A., Wright, W. E., \& Capraro, R. M. (2004). Teaching fractions: Strategies used for teaching fractions to middle grades students. Journal of Research in Childhood Education, 18(3), 193-198.

National Council of Teachers of Mathematics (NCTM) (2014). Principles to action: Ensuring mathematics success for all. Reston, VA: Author.

Novick, L. R. (2004). Diagram literacy in preservice math teachers, computer science majors, and typical undergraduates: The case of matrices, networks, and hierarchies. Mathematical Thinking and Learning, 6(3), 307-342.

Pantziara, M., Gagatsis, A., \& Elia, I. (2009). Using diagrams as tools for the solution of non-routine mathematical problems. Educational Studies in Mathematics, 72(1), 39-60.

Pino-Fan, L. R., Assis, A., \& Castro, W. F. (2015). Towards a Methodology for the Characterization of Teachers' Didactic-Mathematical Knowledge. Eurasia Journal of Mathematics, Science \& Technology Education, 11(6), 1429-1456.

Rau, M. A. (2016). Conditions for the effectiveness of multiple visual representations in enhancing STEM learning. Educational Psychology Review, 1-45.

Roberts, A. L., Sharma, M., Sefton, I. M., \& Khachan, J. (2008). Differences in two evaluations of answers to a conceptual physics question: A preliminary analysis. International Journal of Innovation in Science and Mathematics Education (formerly CAL-laborate International), 16(1), 28-38.

Sherry, D. (2009). The role of diagrams in mathematical arguments. Foundation of Science, 14, 59-74.

Thompson, P. W., \& Saldanha, L. (2003). Fractions and multiplicative reasoning. In J. Kilpatrick, \& G. Martin (Eds.), Research companion to the NCTM Standards (pp. 95-113). Washington, DC: National Council of Teachers of Mathematics.

Way, J., Bobis, J., \& Anderson, J. (2015). Teacher representations of fractions as a key to developing their conceptual understanding. In K. Beswick, T. Muir, \& J. Wells (Eds.), Proceedings of $39^{\text {th }}$ Psychology of Mathematics Education conference (vol. 4, pp. 281-288). Hobart, Australia: PME. 